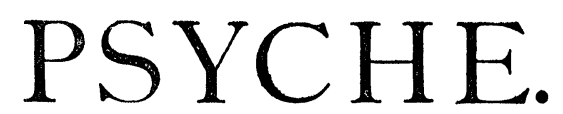

ORGAN OF THE CAMBRIDGE ENTOMOLOGICAL CLUB EDITED BY B. PICKMAN MANN.

Vol. I.] Cambridge, Mass., November, 1875. [No. 19.

\title{
On a supposed Case of Seasonal Dimorphism among Diptera.
}

Seasonal dimorphism is a constantly recurring disparitygreat or small, between two successive broods of the same species during the same year. The attention of entomologists was recalled to this perhaps too little noticed phenomenon by Dr. Weismann's recent publication concerning some cases of seasonal dimorphism among Lepidoptera (Ueber d. Saison-Dimor, phismus $d$. Schmetterlinge). I am strongly inclined to think that the case I intend to notice here, belongs to the same order of phenomena, among Diptera. It was for the first time brought forward by me in a recent paper on the genus Syrphus, published in the Proc. Bost. Soc. Nat. Hist., xviii (Oct. 1875); but $I$ deem it useful to bring it before a larger circle of entomological readers, and thus to invite further investigation.

In preparing the above-mentioned paper on Syrphus, I had the opportunity to examine about 300 specimens of the most common species of this genus in New England, a species closely allied to, if not identical with, the European $S$. ribesii Linné. The result of this examination was, that I distinguished two well marked forms, each represented in both sexes, and which may be defined as follows :

I. $\hat{o}, q$. Eyes pubescent; hind femora black, except at the tip;

II. $\hat{s}, q$. Eyes glabrous ;

$\delta$, all the femora black at the base ; hind femora black, except the tip;

$q$ all the femora vellow from the very base (the coxæ being black); hind femora often with a brown ring before the tip. 
The first of these forms I named Syrphus torvus, the second S. rectus. Between the males of these forms there is hardly any difference at all, except, as just shown, in the condition of the eyes, pubescent in the one, glabrous in the other. Between the females, the difference consists, besides the condition of the eyes, in the color of the lind femora. Minor differences existing between the two forms, are almost unappreciable, and would have been neglected, without the help of those leading characters.

As both forms occur in large numbers in the same localities (my specimens were principally from the White Mountains), the question naturally arises whether they occur promiscuously, or at different seasons? The answer would have been easy, if the dates of the capture of each of those 300 specimens had been noted. Although this was not the case for a considerable majority among them, still, from the data in my possession, it seems probable that $S$. torvus is the form commonly occurring in the early summer, $S$. rectus that of the late summer and autumn. If such is the case, the next question would be whether these two forms are distinct species, or whether they represent a case of seasonal dimorphism of the same species? The latter alternative seems to me the more probable, although of course it would require further proof, by way of observation and experiment, before being accepted.

About ten years ago, Mr. Malm in Göteborg, Sweden, expressed the opinion that the representatives of my $S$. rectus and $S$. torvus in Europe, $S$. ribesii, $S$. vitripennis and $S$. topiarius are not species, but only varieties, each occurring more abundantly in its own season: topiarius (torvus), in the spring; ribesii (rectus), in autumn; and vitripennis between the two, in midsummer. There seems to be a difference, however, between the case, as it stands in Europe, and as I find it here. The European S. vitripennis is said to be an intermediate form between the two other species; it has glabrous eyes, but at the same time the femora of the female are dark at the base. Among the 300 American specimens which I have examined, there was not a single case of this kind: as shown above, all the females with glabrous eyes have the femora yellow from the 
very base. Mr. Malm also found other passages from one form to the other, tending to establish their specific identity: for him, therefore, these forms are varieties; while in America, as far at least as my observation goes, the two forms are perfectly distinct, and thus are either distinct species or dimorphic forms of the same species.

Although the technical particulars, into which I was obliged to enter, are too dry for the general reader, the interest attached to the question thus raised reaches beyond the scope of mere descriptive entomology; and this may be my excuse for bringing this matter before the readers of Рsyche. For more details, I refer to my paper in the above-quoted Proceedings.

C. R. Osten Sacken.

\section{BIBLIOGRAPHICAL RECORD.}

Authors and Societies are requested to forward their works to the Editor at the earliest date possible. We ask our readers to inform us of the publication especially of those works which are not generally consulted by entomologists.

B. Pickman Mann.

(Continued from page 112.)

* 290. The Amer. Nat., vol. ix, as far as p. 576, contains the following, and Nos. 291 to 307.

a. Notice of LeBaron's Fourth Annual Report on the Noxious and Beneficial Insects of the State of Illinois (1874), p. 53 ; of Packard's proposed monograph of Geometrid moths [with request for assistance] (by A. S. Packard, Jr.), pp. 64, 179-180, with figures; of Simon's Les Arachnides de Franec, Tome 1 (1874) (by J. H. Emerton), p. 108-109; of Weyenbergh's * Sobre un Monstruo Dicéfalo (Larva de Chironomus) [etc.] [Periódico Zoológico, Tom. I, p. 50-57, with a figure] (1874), p. 179; of Lubbock's On British Wild Flowers considered in Relation to Insects (1875), p. 245-246; of Scudder's The Distribution of Insects in New Hampshire (1874) p. 309; of Morse's First Book of Zoology (1875), p. 571. b. Note on Telea Polyphemus [corrections of and additions to the article cited in Rec., No. 289] (by A. R. Grote), p. 113-114. c. Obituary notice of Dr. Gideon Lincecum, p. 191. d. Filaria in the House Fly [see Rec., No. 25.9], p. 247. e. Danger of using Paris Green in killing Potato Beetles (by R. U. Piper), p. 318. f. Cigars Destroyed by Insects [Catorama simplex, Xyloteres? sp., Calandra oryzae ], p. 375. g. Entomological announcements for the Detroit meeting of the A. A. A. S. (Aug. 1875), p. 380. $h$. Appointment of Prof. Cyrus Thomas as State Entomologist of Illinois, p. 383. i. Fertilization of Alpine Flowers by Butterflies, p. 421-422. $j$. Notice of the 

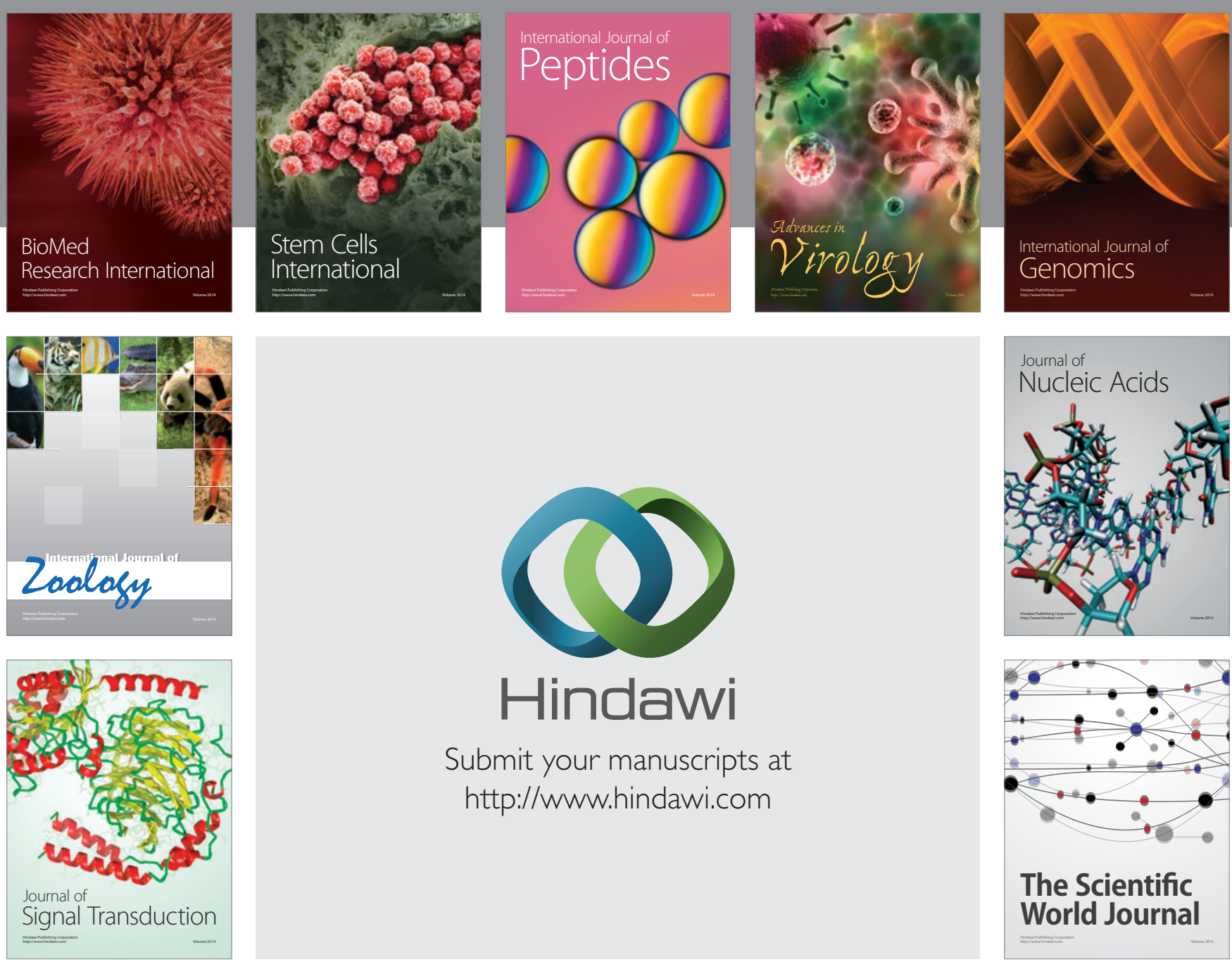

Submit your manuscripts at

http://www.hindawi.com
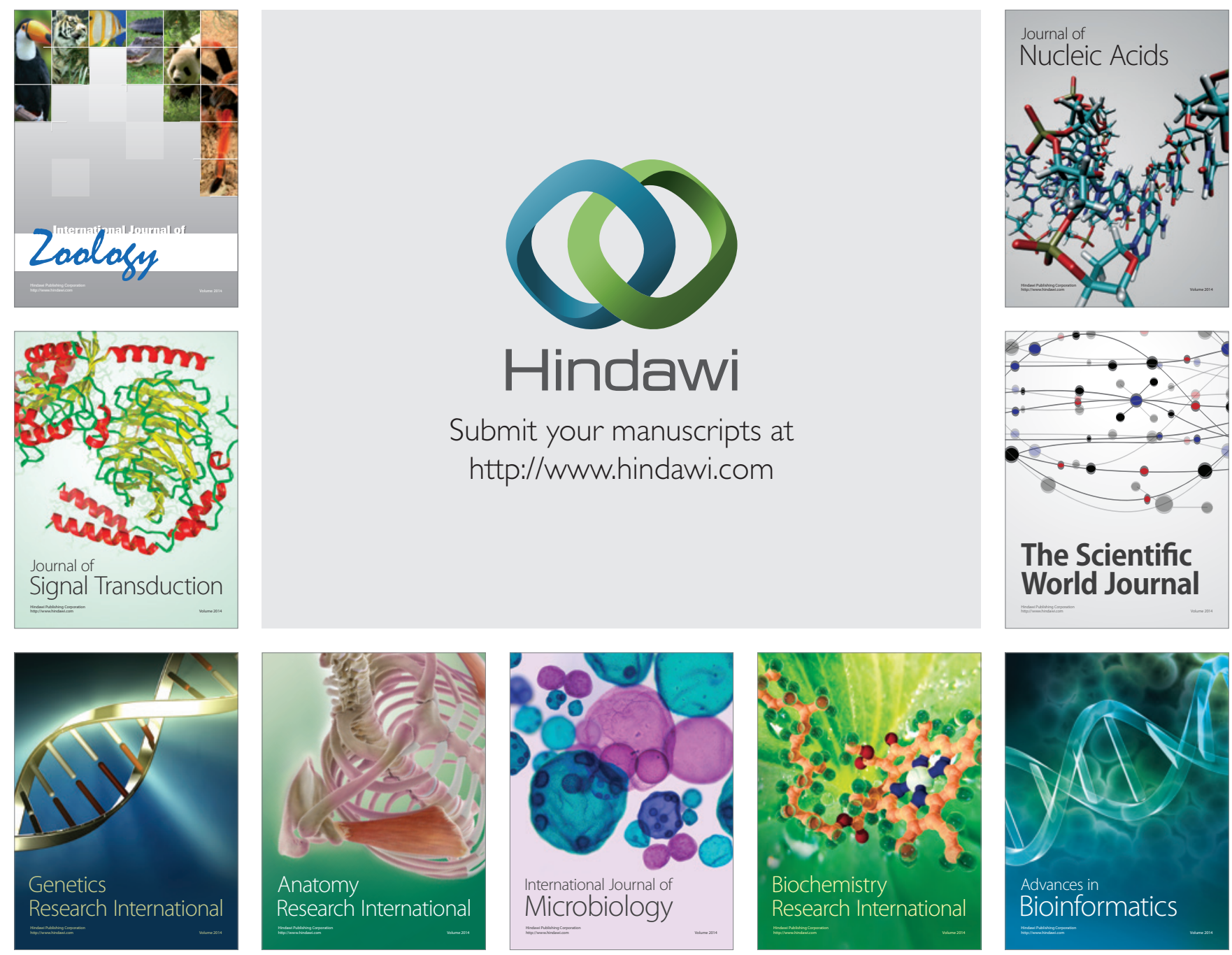

The Scientific World Journal
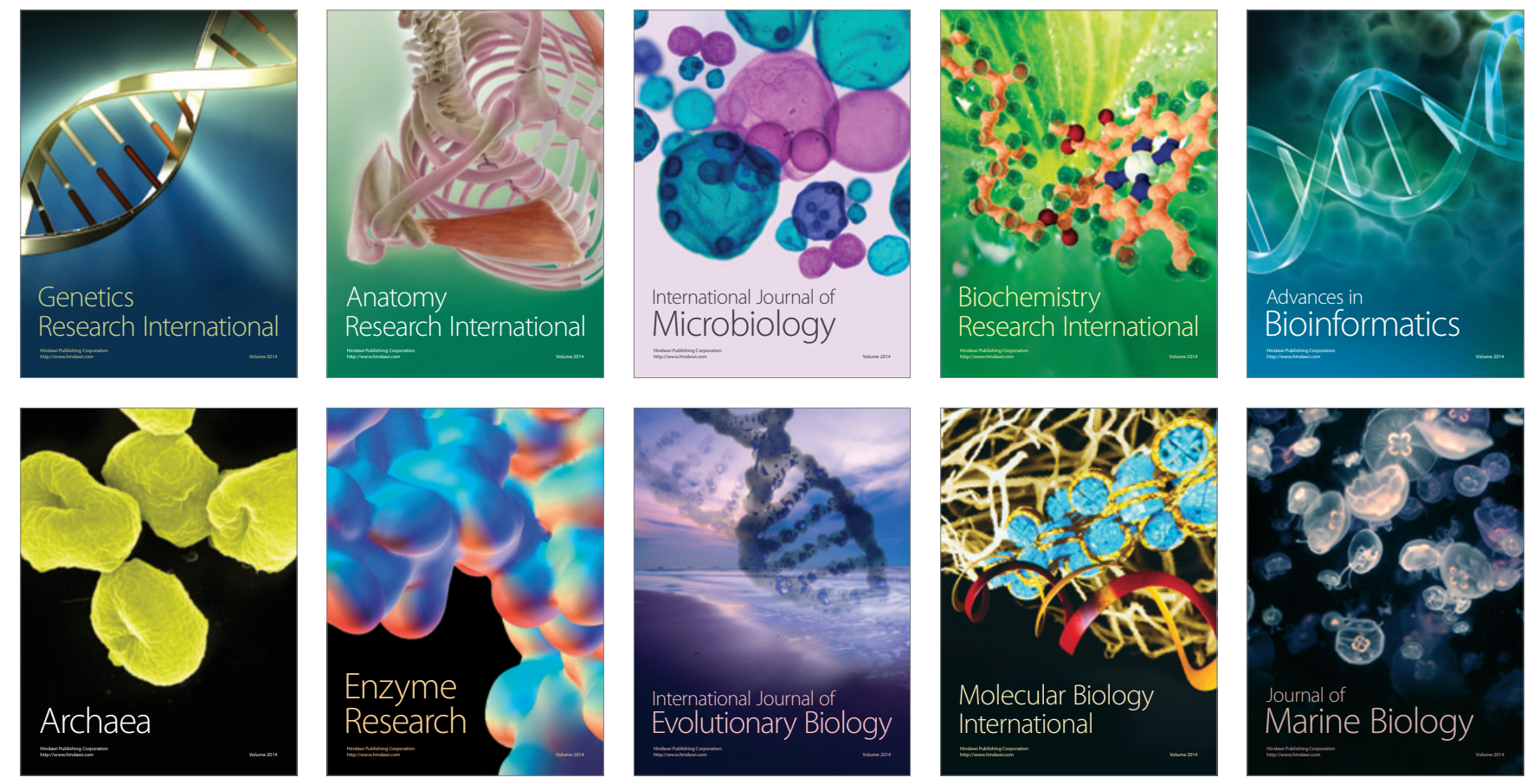